\title{
Determinants of Low Birth Weight among Newborns Delivered at Public Hospitals in Sidama Zone, South Ethiopia: Unmatched Case-Control Study
}

\author{
Muse Bututa Bekela $\mathbb{D}^{1},{ }^{1}$ Mulugeta Shegaze Shimbre $\mathbb{D}^{2},{ }^{2}$ Teshale Fikadu Gebabo ${ }^{D}{ }^{2}$ \\ Mengesha Boko Geta ${ }^{D},{ }^{1}$ Abayneh Tunje Tonga ${ }^{D},{ }^{2}$ Eshetu Andarge Zeleke ${ }^{(D)}{ }^{2}$ \\ Negussie Boti Sidemo $\mathbb{D}^{2}$, and Agegnehu Bante Getnet $\mathbb{D}^{3}$ \\ ${ }^{1}$ Bona District Hospital, Bona, Sidama Zone, Ethiopia \\ ${ }^{2}$ College of Medicine and Health Sciences, School of Public Health, Arba Minch University, Ethiopia \\ ${ }^{3}$ College of Medicine and Health Sciences, School of Nursing, Arba Minch University, Ethiopia
}

Correspondence should be addressed to Teshale Fikadu Gebabo; fikaduteshale1@gmail.com

Received 4 December 2019; Accepted 31 March 2020; Published 16 April 2020

Academic Editor: Olav Lapaire

Copyright (c) 2020 Muse Bututa Bekela et al. This is an open access article distributed under the Creative Commons Attribution License, which permits unrestricted use, distribution, and reproduction in any medium, provided the original work is properly cited.

\begin{abstract}
Low birth weight is a global public health problem having various severe and life-threatening health effects. The World Health Organization is working to reduce the prevalence of low birth weight to $30 \%$ by the year 2025 . Pinpointing the determinants of low birth weight at different scenarios is crucial to reduce the rate of low birth weight in low-income countries which consist of $96.5 \%$ of global low birth weight newborns. Thus, the aim of this study was to assess determinants of low birth weight in Sidama Zone public hospitals of South Ethiopia. An institution-based case-control study was conducted from March 1 to May 5, 2019, in Sidama Zone public hospitals. Data were collected from 354 mother-neonate samples with 118 of them having newborns with birth weight $<2500 \mathrm{~g}$ (cases) and 236 of them having birth weight $\geq 2500 \mathrm{~g}$ (controls) using a pretested, intervieweradministered structured questionnaire and medical record review. The odds of being rural dweller women was 3.51 times higher among cases (low birth weight babies) than among controls (normal birth weight babies) as compared to being urban dweller women $(\mathrm{AOR}=3.51,95 \% \mathrm{CI}(1.91-6.45))$. The likelihood of initiating antenatal care late was 3.22 times more among cases than among controls when compared with timely initiation of antenatal care (AOR $=3.22,95 \%$ CI $(1.47-7.14)$ ). The probability of having pregnancy-induced hypertension was 4.49 times higher among mothers of the cases than among mothers of the controls as compared to not having pregnancy-induced hypertension ( $\mathrm{AOR}=4.49,95 \% \mathrm{CI}(1.94-10.38)$ ). The odds of not taking iron and folic acid during pregnancy was 3.92 times higher among mothers of the cases than mothers of the controls when compared with taking iron and folic acid $(\mathrm{AOR}=3.92,95 \% \mathrm{CI}(1.80-8.50)$ ). The likelihood of having Mid-Upper Arm Circumference (MUAC) $<23 \mathrm{~cm}$ was 4.27 times higher among mothers of the cases than among mothers of the controls as compared to having $M U A C \geq 23 \mathrm{~cm}(\mathrm{AOR}=4.27,95 \% \mathrm{CI}(2.24-8.12))$. The probability of having inadequate dietary diversity was 3.75 times higher among cases than among controls as compared to having adequate dietary diversity ( $\mathrm{AOR}=3.75,95 \% \mathrm{CI}$ (1.64-8.57)). Interventions targeting the aversion of low birth weight should focus on promotion of iron-folic acid supplementation and dietary diversification through timely initiation of antenatal care.
\end{abstract}

\section{Introduction}

A newborn's weight at birth is a vital indicator of maternal nutritional status and fetal health [1]. Globally, low birth weight (LBW) constitutes a major public health problem and is one of the main causes of newborn death $[2,3]$. Every year, more than 20 million newborns are delivered with LBW $[3,4]$; of these, over $96.5 \%$ occur in low-income countries. About 5.7 million African newborns are delivered with LBW $[1,5]$, and Ethiopia contributes $13 \%$ to this figure [6]. 
The magnitude of LBW varies across regions within countries [7-17].

With regard to its consequence, about 2.5 million and 23,091 newborns die every year due to LBW across the world and in Ethiopia, respectively $[2,18]$. It also executes a remarkable burden on the social, economic, and healthcare system [7]. Low birth weight has various life-threatening and long-term consequences $[1,4,19]$. Newborns with birth weight less than $2500 \mathrm{~g}$ were about 20 times more likely to die than a newborn with normal birth weight [20]. Newborns with LBW stay in the hospital for a long time (average of 12.9 days) after birth which is far higher as compared to those with normal birth weight $[21,22]$. This is based on epidemiological observations that newborns delivered with birth weight below 2500 grams are at higher risk of mortality when compared to those with normal birth weight [20].

Existing evidences from different parts of the world showed that the causes of low birth weight have been broadly grouped into individual-related, provider-related, and health service-related factors [16, 23-28].

The WHO has set a policy to reduce the prevalence of LBW by $30 \%$ at the end of 2025 [3]. This has been set for Ethiopia to a rate of $7 \%$ as the country is working in line with the global recommendations [29]. Promoting birth spacing, providing prenatal care, and strengthening the referral system and prevention of malaria and intestinal parasites, antibiotic treatment for bacterial infections, and prevention and control of hypertension during pregnancy were some of the interventions done to reduce LBW [3]. However, the progress in reducing global LBW has been stagnant since the year 2000 particularly during the most recent period from 2010 to 2015 [1]. Hardly was it rising in Ethiopia: 11\% in 2011 and 13\% in 2016 [6]. A recent systematic review in Ethiopia has come up with a pooled prevalence of LBW of $17.3 \%$ even though the study considered data from surveys done years ago [30].

Despite several studies being conducted in a different part of Ethiopia, the majority were reported from small settings and urban populations, which may underestimate the effect of possible risk factors from the rural population. This study is relatively a comprehensive study which covers more than 30 districts to determine predictors of LBW among newborns in public hospitals of Sidama Zone, South Ethiopia, where recent studies investigating the problem were not common. Thus, the study would give an input to programmatic interventions and policy considerations in the region and by extension to Ethiopia.

\section{Methods}

2.1. Study Setting, Design, and Population. An institutionbased case-control study was conducted in Sidama Zone public hospitals from March 1 to May 5, 2019. Sidama Zone is one of 18 zones of the Southern Nations, Nationalities, and Peoples' Region (SNNPR) of Ethiopia. It is located $272 \mathrm{~km}$ to the south east of Addis Ababa, the capital city of Ethiopia. The zone has a total area of 6981.8 square kilometers and is administratively divided into 31 districts and 6 town administrations. According to the 2018 estimate, the zone has a total population of 4,294,730 ( $49 \%$ females and $51 \%$ males), and the expected number of deliveries was 148,598. Currently, 15 hospitals, 126 health centers, 531 health posts, and 107 private and 7 NGO clinics are providing health service for the population. According to the zonal health department report, the proportion of women who delivered in the health facilities in Sidama Zone in the year 2018/2019 was $71.6 \%$. All mothers with their newborns delivered at public hospitals in Sidama Zone were considered source populations for cases and controls. Cases were newborns with birth weight $<2500 \mathrm{~g}$, and controls were newborns with birth weight $\geq 2500 \mathrm{~g}$.

2.2. Sample Size Determination. Sample size was estimated using OpenEpi software with the consideration of the proportion of rural women among controls $(24.8 \%)$ and the odds ratio of 2.1 [27] and with the assumptions of the confidence level of $95 \%$, power of $80 \%$, and case to control ratio of $1: 2$. After additional consideration of the $10 \%$ nonresponse rate, the total sample size was 354 (118 cases and 236 controls).

2.3. Sampling Procedure. Five hospitals were selected out of 15 public hospitals by using the simple random sampling lottery method. The required sample was allocated proportionally to each hospital based on the number of LBW deliveries reported from each hospital in the year preceding the survey. Cases were selected consecutively, and two controls were also included consecutively for each case. Women with twin deliveries and who were seriously ill during the data collection were excluded from the study.

2.4. Data Collection Procedure and Tools. Data were collected by 10 female diploma holder midwives who speak the local languages fluently. Five male midwives with a bachelor degree were recruited as supervisors. Data collectors interviewed mothers using an interviewer-administered structured questionnaire. The serum hemoglobin level of mothers was extracted from their medical records since the hemoglobin level test is routinely done for all mothers who come for delivery services. The questionnaire was adapted by reviewing different related literatures $[7,22,23,29-41]$.

2.5. Measurements. Weights of the newborns were measured by using a digital Seca balance scale (Germany) to the nearest $1 \mathrm{~g}$. The scale was adjusted to the zero level before weighing each newborn. Height of the mothers was measured using a height board while the mother was in standing position. Each height was taken to the nearest $0.01 \mathrm{~m}$. MUAC of the mother was measured with a nonstretchable standard tape to the nearest $0.1 \mathrm{~cm}$. Minimum Dietary Diversity for Women (MDD-W) was measured by the ten questions developed by FAO and FANTA as a proxy indicator to reflect the micronutrient adequacy of women's diets. Those women who replied "yes" for each food item interviewed were taken as "consumed," and those who replied "no" did not consume anything in the previous 24 hours [31].

2.6. Data Quality Management. Detailed training was given to both data collectors and supervisors in the context of the study and measurement of weight of the newborns and height and 
MUAC of the mothers. The questionnaire was prepared in English and translated to Amharic then retranslated back to English. A pretest was conducted on 5\% of the total sample size one week before the actual data collection. The data collection was supervised, and the collected data were checked for completeness and consistency on a daily basis.

2.7. Data Analysis. The collected data was checked for completeness and then coded, checked, and entered into EpiData version 4.2.1. After completing the entry in EpiData software, the data was exported to SPSS version 20 for cleaning and analysis. Data transformation was done where appropriate. Crosstabulations were made to check for the fulfillment of chi-squared assumptions. Descriptive analysis was conducted and presented using frequency tables and summarized using the mean and standard deviation. To determine the wealth index of participants, a principal component analysis was carried out after checking the fulfillment of assumptions. Women's household wealth was ranked into five groups (quintiles) as poor, second, medium, fourth, and highest from the lowest to the highest quintiles. Bivariate logistic regression was carried out, and variables with $p$ value $\leq 0.25$ were entered into multivariable logistic regression. The multivariable logistic regression model was built using the backward likelihood ratio method in the final model. Model fitness was assessed by using the Hosmer and Lemeshow goodness-of-fit test. Finally, the determinants of LBW were reported by an adjusted odds ratio (AOR) with 95\% confidence interval (CI).

\section{Results}

3.1. Sociodemographic Characteristics of the Study Participants. One hundred eighteen cases (birth weight $<2500$ ) and 236 controls (birth weight $\geq 2500$ ) participated in the study. The mean birth weight was $2089 \mathrm{~g}$ (SD $\pm 260 \mathrm{~g}$ ) and $3181 \mathrm{~g}$ (SD $\pm 358 \mathrm{~g}$ ) for the cases and controls, respectively. More than half of the cases $(61(51.7 \%))$ and controls $(140(59.3 \%))$ were males. Majority of mothers of the cases (107 (90.7\%)) and controls (215 (91.1\%)) were married; most of the mothers of the study participants among cases $(81(68.6 \%))$ and controls (176 $(74.6 \%)$ ) were between the age of 20 and 34 years. Similarly, 107 (90.7\%) mothers of cases and 148 (62.7\%) mothers of controls were taking inadequate minimum dietary diversity (Table 1).

3.2. Obstetric and Other Health-Related Characteristics of Mothers of the Study Participants. Fifty-one (43.2\%) mothers of cases and $82(34.7 \%)$ mothers of controls were Prim-Para. Similarly, 23 (34.3\%) mothers of cases and 44 (28.6\%) mothers of controls had a history of low birth weight, and also 18 (26.9\%) mothers of cases and $31(20.1 \%)$ controls had a history of stillbirth. With regard to their pregnancy intention, 50 (42.4\%) mothers of cases and 98 (41.5\%) mothers of controls had unintended pregnancy. Thirty-four (28.8\%) mothers of cases and 54 (22.9\%) mothers of controls were having preterm deliveries (Table 2).

3.3. Factors Associated with Low Birth Weight. A total of thirteen variables with $p$ value $<0.25$ in the bivariate analysis were included in multivariable logistic regression. The odds of being rural dweller women was 3.51 times higher among cases (low birth weight babies) than among controls (normal birth weight babies) as compared to being urban dweller women $(\mathrm{AOR}=3.51,95 \% \mathrm{CI}(1.91-6.45))$. The likelihood of initiating antenatal care late was 3.22 times more among cases than among controls when compared with timely initiation of antenatal care (AOR $=3.22,95 \%$ CI (1.47-7.14)). The probability of having pregnancy-induced hypertension was 4.49 times higher among mothers of the cases than among mothers of the controls as compared to not having pregnancy-induced hypertension (AOR $=4.49,95 \%$ CI (1.94-10.38)). The odds of not taking iron and folic acid during pregnancy was 3.92 times higher among mothers of the cases than among mothers of the controls when compared with taking iron and folic acid (AOR $=3.92,95 \% \mathrm{CI}(1.80$ 8.50)). The likelihood of having Mid-Upper Arm Circumference $(\mathrm{MUAC})<23 \mathrm{~cm}$ was 4.27 times higher among mothers of the cases than among mothers of the controls as compared to having MUAC $\geq 23 \mathrm{~cm}(\mathrm{AOR}=4.27,95 \% \mathrm{CI}$ (2.24-8.12)). The probability of having inadequate dietary diversity was 3.75 times higher among cases than among controls as compared to having adequate dietary diversity $(\mathrm{AOR}=3.75,95 \% \mathrm{CI}(1.64-8.57))$ (Table 3$)$.

\section{Discussion}

The odds of being rural dweller women was higher among cases (low birth weight babies) than among controls (normal birth weight babies) as compared to being urban dweller women. The low accessibility of health facility and maternal health service utilization in a rural area might increase the likelihood of having LBW infants. This finding was consistent with studies conducted in Ethiopia and Zimbabwe [27, $32,33]$. But it is inconsistent with a study conducted in another part of Ethiopia [13]. This discrepancy might be due to differences in the study settings where our study area covered both urban and rural hospitals and the latter study was conducted in an urban setting where a teaching and referral hospital was also included.

The likelihood of initiating antenatal care late was more among cases than among controls when compared with timely initiation of antenatal care. This finding is in line with studies conducted in Algeria, Nepal, and Ethiopia [26, 34-36]. This might be due to the fact that a woman who visits the health facility timely for ANC might have a better opportunity for dietary counseling and iron and folic acid supplementation, adequate time for iron absorption from the gastrointestinal tract, and timely detection and treatment of different infections [20]. As a result, the likelihood of having a low birth weight baby would be less as compared to their counterparts.

This study indicated that the maternal history of pregnancy-induced hypertension was found to be an independent factor contributing to low birth weight where the probability of having pregnancy-induced hypertension was higher among mothers of the cases than among mothers of the controls as compared to not having pregnancy-induced hypertension. This finding is in line with studies conducted 
TABLE 1: Sociodemographic characteristics of the study participants from public health hospitals of Sidama Zone, South Ethiopia, 2019.

\begin{tabular}{|c|c|c|c|}
\hline Variables & $\begin{array}{c}\text { Cases } \\
\text { No. }(\%)\end{array}$ & $\begin{array}{l}\text { Controls } \\
\text { No. }(\%)\end{array}$ & $p$ value \\
\hline \multicolumn{4}{|l|}{ Sex of the newborn } \\
\hline Male & $61(51.7)$ & $140(59.3)$ & \multirow[t]{2}{*}{0.173} \\
\hline Female & $57(48.3)$ & $96(40.7)$ & \\
\hline \multicolumn{4}{|l|}{ Maternal age } \\
\hline$<20$ years & $21(17.8)$ & $33(14.0)$ & \multirow{3}{*}{0.491} \\
\hline 20 to 34 years & $81(68.6)$ & $176(74.6)$ & \\
\hline$\geq 35$ years & $16(13.6)$ & $27(11.4)$ & \\
\hline \multicolumn{4}{|l|}{ Residence } \\
\hline Urban & $38(32.2)$ & $139(58.9)$ & \multirow[t]{2}{*}{0.001} \\
\hline Rural & $80(67.8)$ & $97(41.1)$ & \\
\hline \multicolumn{4}{|l|}{ Marital status } \\
\hline Married & $107(90.7)$ & $215(91.1)$ & \multirow[t]{2}{*}{0.899} \\
\hline Separated and divorced & $11(9.3)$ & $21(8.9)$ & \\
\hline \multicolumn{4}{|l|}{ Maternal level of education } \\
\hline Unable to read and write & $57(48.3)$ & $75(31.8)$ & \multirow{4}{*}{0.003} \\
\hline Primary school & $31(26.3)$ & $74(31.4)$ & \\
\hline Secondary school & $22(18.6)$ & $50(21.2)$ & \\
\hline Above secondary & $8(6.8)$ & $37(15.7)$ & \\
\hline \multicolumn{4}{|l|}{ Occupation of mother } \\
\hline Housewife & $47(39.8)$ & $81(34.3)$ & \multirow{5}{*}{0.624} \\
\hline Merchant & $21(17.8)$ & $50(21.2)$ & \\
\hline Farmer & $16(13.6)$ & $41(17.4)$ & \\
\hline Student & $20(16.9)$ & $32(13.6)$ & \\
\hline Employed & $14(11.9)$ & $32(13.6)$ & \\
\hline \multicolumn{4}{|l|}{ Wealth index of household } \\
\hline Lowest & $31(26.3)$ & $58(24.6)$ & \multirow{5}{*}{0.453} \\
\hline Second & $13(11.0)$ & $39(16.5)$ & \\
\hline Middle & $21(17.8)$ & $46(19.5)$ & \\
\hline Fourth & $34(28.8)$ & $51(21.6)$ & \\
\hline Highest & $19(16.1)$ & $42(17.8)$ & \\
\hline \multicolumn{4}{|l|}{ MUAC } \\
\hline$<23 \mathrm{~cm}$ & $58(49.2)$ & $38(16.1)$ & \multirow[t]{2}{*}{0.001} \\
\hline$\geq 23 \mathrm{~cm}$ & $60(50.8)$ & $198(83.9)$ & \\
\hline \multicolumn{4}{|l|}{ Height } \\
\hline$<150 \mathrm{~cm}$ & $15(12.7)$ & $13(5.5)$ & \multirow[t]{2}{*}{0.018} \\
\hline$\geq 150 \mathrm{~cm}$ & $103(87.3)$ & $223(94.5)$ & \\
\hline \multicolumn{4}{|l|}{ Minimum dietary diversity } \\
\hline Inadequate & $107(90.7)$ & $148(62.7)$ & \multirow[t]{2}{*}{0.001} \\
\hline Adequate & $11(9.3)$ & $88(37.3)$ & \\
\hline
\end{tabular}

in Ethiopia, Malaysia, Nepal, and Gambia [25, 26, 28, 37, 38]. This might be because blood vessel constriction reduces oxygen and nutrient perfusion to the placenta which leads to an increased risk of intrauterine growth restriction which leads to undernutrition which in turn exposes babies to low birth weight $[3,20]$.

The odds of not taking iron and folic acid during pregnancy was higher among mothers of the cases than among mothers of the controls when compared with taking iron and folic acid. This finding is comparable with studies conducted in different parts of Ethiopia [15, 16, 23, 24, 32, 35]. This might be because iron and folic acid intake during pregnancy reduces the risk of anemia and subsequently decreases the likelihood of having low birth weight newborns [24].

The likelihood of having Mid-Upper Arm Circumference (MUAC) $<23 \mathrm{~cm}$ was higher among mothers of the cases than among mothers of the controls as compared to having 
TABle 2: Obstetric-related characteristics of the study participants from public health hospitals of Sidama Zone, South Ethiopia, 2019.

\begin{tabular}{|c|c|c|c|}
\hline Variables & $\begin{array}{c}\text { Cases } \\
\text { No. }(\%)\end{array}$ & $\begin{array}{l}\text { Controls } \\
\text { No. }(\%)\end{array}$ & $p$ value \\
\hline \multicolumn{4}{|l|}{ Parity } \\
\hline Prim-Para & $51(43.2)$ & $82(34.7)$ & \multirow[t]{2}{*}{0.120} \\
\hline Multi-Para & $67(56.8)$ & $154(65.3)$ & \\
\hline \multicolumn{4}{|l|}{ History of LBW } \\
\hline Yes & $23(34.3)$ & $44(28.6)$ & \multirow[t]{2}{*}{0.392} \\
\hline No & $44(65.7)$ & $110(71.4)$ & \\
\hline \multicolumn{4}{|c|}{ History of stillbirth } \\
\hline Yes & $18(26.9)$ & $31(20.1)$ & \multirow[t]{2}{*}{0.267} \\
\hline No & $49(73.1)$ & $123(79.9)$ & \\
\hline \multicolumn{4}{|l|}{ Birth interval } \\
\hline$\geq 2$ years & $47(70.1)$ & $115(74.7)$ & \multirow[t]{2}{*}{0.484} \\
\hline$<2$ years & $20(29.9)$ & $39(25.3)$ & \\
\hline \multicolumn{4}{|c|}{ History of abortion } \\
\hline Yes & $19(16.1)$ & $31(13.1)$ & \multirow[t]{2}{*}{0.450} \\
\hline No & $99(83.9)$ & $205(86.9)$ & \\
\hline \multicolumn{4}{|l|}{ Pregnancy status } \\
\hline Intended & $68(57.6)$ & $138(58.5)$ & \multirow[t]{2}{*}{0.881} \\
\hline Unintended & $50(42.4)$ & $98(41.5)$ & \\
\hline \multicolumn{4}{|l|}{ Anemia } \\
\hline Yes & $28(23.7)$ & $33(14.0)$ & \multirow[t]{2}{*}{0.022} \\
\hline No & $90(76.3)$ & $203(86.0)$ & \\
\hline \multicolumn{4}{|l|}{ Gestational age } \\
\hline Preterm & $34(28.8)$ & $54(22.9)$ & \multirow[t]{2}{*}{0.223} \\
\hline Term & $84(71.2)$ & $182(77.1)$ & \\
\hline \multicolumn{4}{|c|}{ Ever attended ANC } \\
\hline Yes & $105(89.0)$ & $216(91.5)$ & \multirow[t]{2}{*}{0.438} \\
\hline No & $13(11.0)$ & $20(8.5)$ & \\
\hline \multicolumn{4}{|c|}{ Time of ANC initiation } \\
\hline $1^{\text {st }}$ trimester & $16(15.2)$ & $78(36.1)$ & \multirow{3}{*}{0.001} \\
\hline $2^{\text {nd }}$ trimester & $29(27.6)$ & $71(32.9)$ & \\
\hline $3^{\text {rd }}$ trimester & $60(57.2)$ & $67(31.0)$ & \\
\hline \multicolumn{4}{|c|}{ Number of ANC visit } \\
\hline$<4$ times & $70(66.7)$ & $130(60.2)$ & \multirow[t]{2}{*}{0.26} \\
\hline$\geq 4$ times & $35(33.3)$ & $86(39.8)$ & \\
\hline \multicolumn{4}{|c|}{ Dietary counseling } \\
\hline Yes & $52(49.5)$ & $120(56.1)$ & \multirow[t]{2}{*}{0.27} \\
\hline No & $53(50.5)$ & $94(43.9)$ & \\
\hline \multicolumn{4}{|c|}{ Iron and folic acid supplementation } \\
\hline Yes & $15(14.3)$ & $104(48.1)$ & 0.001 \\
\hline No & $53(85.7)$ & $112(51.9)$ & \\
\hline Pregnancy-indu & & & \\
\hline Yes & $28(23.7)$ & $29(12.3)$ & 0.005 \\
\hline No & $90(76.3)$ & $207(87.7)$ & \\
\hline
\end{tabular}

MUAC $\geq 23 \mathrm{~cm}$. This might be explained by the mistaken perception of women that frequent and much diet consumption during pregnancy could lead to excessive fetal growth which they perceive would be beyond tolerance of the birth canal and pose difficulty during childbirth $[32,39]$. Due to this, pregnant women might not take adequate food; thus, they might be prone to undernutrition and can have low birth weight newborns. The effect of malnutrition has an intergenerational continuum; if a mother was malnourished during pregnancy, the likelihood of having a low birth weight 
TABLE 3: Determinants of LBW among newborns delivered at public hospitals of Sidama Zone, South Ethiopia, 2019.

\begin{tabular}{|c|c|c|c|c|}
\hline Variables & $\begin{array}{c}\text { Cases } \\
\text { No. }(\%)\end{array}$ & $\begin{array}{l}\text { Controls } \\
\text { No. }(\%)\end{array}$ & COR $(95 \% \mathrm{CI})$ & AOR (95\% CI) \\
\hline \multicolumn{5}{|l|}{ Residence } \\
\hline Rural & $80(67.8)$ & $97(41.1)$ & $3.03(1.90-4.80)$ & $3.51(1.91-6.45)$ \\
\hline Urban & $38(32.2)$ & $139(58.9)$ & 1 & 1 \\
\hline \multicolumn{5}{|c|}{ Time of ANC initiation } \\
\hline $1^{\text {st }}$ trimester & $16(15.2)$ & $78(36.1)$ & 1 & 1 \\
\hline $2^{\text {nd }}$ trimester & $29(27.6)$ & $71(32.9)$ & $2.17(1.33-3.84)$ & $0.80(0.39-1.66)$ \\
\hline $3^{\text {rd }}$ trimester & $67(57.2)$ & $67(31.0)$ & $4.35(2.27-8.33)$ & $3.23(1.47-7.14)$ \\
\hline \multicolumn{5}{|c|}{ Pregnancy-induced HTN } \\
\hline Yes & $28(23.7)$ & $29(12.3)$ & $2.22(1.25-3.95)$ & $4.49(1.94-10.38)$ \\
\hline No & $90(76.3)$ & $207(87.7)$ & 1 & 1 \\
\hline \multicolumn{5}{|c|}{ Iron \& folic acid supplementation } \\
\hline Yes & $15(14.3)$ & $104(48.1)$ & 1 & 1 \\
\hline No & $90(85.7)$ & $112(51.9)$ & $5.57(3.03-10.2)$ & $3.92(1.80-8.5)$ \\
\hline \multicolumn{5}{|c|}{ Mid-Upper Arm Circumference } \\
\hline$<23 \mathrm{~cm}$ & $58(49.2)$ & $38(16.1)$ & $5.04(3.05-8.3)$ & $4.27(2.24-8.1)$ \\
\hline$\geq 23 \mathrm{~cm}$ & $60(50.8)$ & $198(83.9)$ & 1 & 1 \\
\hline \multicolumn{5}{|c|}{ Dietary diversity during pregnancy } \\
\hline Inadequate & $107(90.7)$ & $148(62.7)$ & $5.78(2.95-11.3)$ & $3.75(1.64-8.5)$ \\
\hline Adequate & $11(9.3)$ & $88(37.3)$ & 1 & 1 \\
\hline
\end{tabular}

infant will be high. This finding was consistent with studies conducted in Ethiopia [23, 24, 40]. In this study, dietary diversity during pregnancy was found to be an independent contributing factor of low birth weight where the probability of having inadequate dietary diversity was higher among cases than among controls as compared to having adequate dietary diversity. The possible explanation for this might be the fact that an inadequately diversified diet lacks some essential nutrients which would be essential for fetal growth and development that consequently leads to low birth weight. This finding is in agreement with a study conducted in Ethiopia [24].

Even though the findings on the factors associated with LBW in this study were consistent with the majority of pocket studies in the country, it was not supported by a recent systematic review in Ethiopia [30]. This might be explained by the fact that two-thirds of the studies considered in the review were cross-sectional studies.

The present study has few limitations to consider. The self-reported nature of the determinants based only on the mothers' memory might have a recall bias, and there may also be an intra- or interobserver bias that might have led to misclassification of cases and controls. The data was collected from mothers who gave birth at the health facility limiting its generalizability to all women in the zone as those who gave birth at home have been left out.

\section{Conclusion}

The finding of this study showed that time of antenatal care initiation, the residence of participants, maternal malnutrition measured by Mid-Upper Arm Circumference and inadequate dietary diversity during pregnancy, not getting iron and folic acid supplementation, and having pregnancy-induced hypertension were found to be independent determinants of birth weight among newborn babies. So concerned health authorities and health professionals should strengthen the existing promotion on timely initiation of antenatal care and stick to iron and folic acid supplementation recommendations during the antenatal care. Nutrition education and capacity building should be strengthened during the prenatal care in the local setup and by extension to the country as a whole.

\section{Abbreviations}

ANC: $\quad$ Antenatal care

AOR: Adjusted odds ratio

COR: Crude odds ratio

FANTA: Food and Nutrition Technical Assistance

FAO: $\quad$ Food and Agriculture Organization

LBW: Low birth weight

MDD-W: Minimum Dietary Diversity for Women

MUAC: Mid-Upper Arm Circumference.

\section{Data Availability}

The [SPSS/EXCEL] data used to support the findings of this study are available from the corresponding author upon request.

\section{Ethical Approval}

Ethical clearance was obtained from the Institutional Ethical Review Board of Arba Minch University. A supportive letter was obtained from the Sidama zonal health department. 


\section{Consent}

Informed consent was obtained from the study participants.

\section{Conflicts of Interest}

The authors declare that they have no competing interests.

\section{Authors' Contributions}

MB, MS, and TF are responsible for the design, data entry, data analysis, and interpretation of the result and preparation of the manuscript. TF and EA monitored the overall research undertaking and carried out the scientific writing of the manuscript. $\mathrm{MB}, \mathrm{AT}, \mathrm{EA}, \mathrm{NB}$, and $\mathrm{AB}$ participated in data analysis, interpretation, and preparation of the manuscript. The authors alone were involved in the design, analysis, and interpretation of data and in writing of the manuscript.

\section{Acknowledgments}

We would like to thank Arba Minch University for the provision of ethical clearance and for monitoring our work, and sswe extend our endless thanks to the study participants, data collectors, and supervisors.

\section{References}

[1] UNICEF, WHO, UNICEF-WHO low birth weight estimates: levels and trends 2000-2015, WHO, Geneva, 2019.

[2] UNICEF and UNCs Fund, The State of the World's Children 2009: Maternal and Newborn Health, Unicef, 2008.

[3] WHO, "Global nutrition targets 2025: low birth weight policy brief 2014," https://www.who.int/nutrition/publications/ globaltargets2025_policybrief_lbw/en/.

[4] World Health Organization, Care of the Preterm and Low-BirthWeight Newborn: World Prematurity Day-17 November 2018, World Health Organization, Geneva, 2018, https://www.who .int/maternal_child_adolescent/newborns/prematurity/en/.

[5] H. Sachdev, "Low birth weight in South Asia," International Journal of Diabetes in Developing Countries, vol. 21, no. 1, pp. 13-33, 2001.

[6] Central statistical agency of Ethiopia and ICF, Ethiopia demographic and health survey 2016 Addis Ababa, Ethiopia, and Rockville, Maryland, USA, CSA and ICF, 2016.

[7] R. Mahumud, M. Sultana, and A. Sarker, "Distribution and determinants of low birth weight in developing countries," Journal of Preventive Medicine and Public Health, vol. 50, no. 1, pp. 18-28, 2017.

[8] N. Sharif,, M. Dolatian, A. Fathnezhad, R. Pakzad, Z. Mahmoodi, and F. Nasrabadi, "Prevalence of low birth weight in Iranian newborns: a systematic review and metaanalysis," International Journal of Women's Health and Reproduction Sciences, vol. 6, no. 3, pp. 233-239, 2018.

[9] A. Koirala and D. Bhatta, "Low-birth-weight babies among hospital deliveries in Nepal: a hospital-based study," International Journal of Women's Health, vol. 2015, p. 581, 2015.

[10] S. N. Chakraborty and T. K. Som, "Prevalence and determinants of low birth weight: an experience from a secondary referral unit of BurdwanDistrict, West Bengal (India)," Journal of Dental and Medical Sciences, vol. 17, no. 3, pp. 54-59, 2018.
[11] S. Khan, D. Jhorna, A. Chakma, A. Tareq, and M. R. Begum, "Socio-demographic and nutritional determinants of birth weight," Journal of Food Science and Nutrition, vol. 1, no. 1, pp. 29-32, 2018.

[12] Z. He, G. Bishwajit, S. Yaya, Z. Cheng, D. Zou, and Y. Zhou, "Prevalence of low birth weight and its association with maternal body weight status in selected countries in Africa: a crosssectional study," BMJ Open, vol. 8, no. 8, article e020410, 2018.

[13] S. Kastro, T. Demissie, and B. Yohannes, "Low birth weight among term newborns in Wolaita Sodo town, South Ethiopia: a facility-based cross-sectional study," BMC Pregnancy and Childbirth, vol. 18, no. 1, p. 160, 2018.

[14] T. Tafere, M. Afework, and A. Yalew, "Providers adherence to essential contents of antenatal care services increases birth weight in Bahir Dar City Administration, north west Ethiopia: a prospective follow up study," Reproductive Health, vol. 15, no. 1 , article $163,2018$.

[15] Y. Gebregzabiherher, A. Haftu, S. Weldemariam, and H. Gebrehiwet, "The prevalence and risk factors for low birth weight among term newborns in Adwa General Hospital, Northern Ethiopia," Obstetrics and Gynecology International, vol. 2017, Article ID 2149156, 7 pages, 2017.

[16] W. Kumlachew, N. Tezera, and A. Endalamaw, "Below normal birth weight in the Northwest part of Ethiopia," BMC Research Notes, vol. 11, no. 1, p. 611, 2018.

[17] L. Girma, "The association between maternal characteristics and low birth weight delivery among neonates delivered in Gandhi Hospital, Addis Ababa: a cross-sectional study," Journal of Family Medicine \& Community Health, vol. 5, no. 3, 2018.

[18] World Health Organizatio, "World life expectancy. Low birth weight in Ethiopia USA 2017," https://www .worldlifeexpectancy.com/ethiopia.

[19] I. Manual, Very low and extremely low birthweight infants, The Regents of the University of California, 2004.

[20] UNICEF, Low birthweight: country, regional and global estimatesWHO, New Yorkhttps://www.unicef.org.

[21] S. E. Black, P. J. Devereux, and K. G. Salvanes, "From the cradle to the labor market? The effect of birth weight on adult outcomes," The Quarterly Journal of Economics, vol. 122, no. 1, pp. 409-439, 2007.

[22] R. B. Russell, N. S. Green, C. A. Steiner et al., "Cost of hospitalization for preterm and low birth weight infants in the United States," Pediatrics, vol. 120, no. 1, pp. e1-e9, 2007.

[23] G. Asmare, N. Berhan, M. Berhanu, and A. Alebel, "Determinants of low birth weight among neonates born in Amhara Regional State Referral Hospitals of Ethiopia: unmatched case control study," BMC Research Notes, vol. 11, no. 1, article 447, 2018.

[24] S. Ahmed, K. Hassen, and T. Wakayo, "A health facility-based case-control study on determinants of low birth weight in Dassie town, Northeast Ethiopia: the role of nutritional factors," Nutrition Journal, vol. 17, no. 1, article 103, 2018.

[25] R. Sutan, M. Mohtar, A. Mahat, and A. Tamil, "Determinant of low birth weight infants: a matched Case Control study," Open Journal of Preventive Medicine, vol. 4, no. 3, pp. 91-99, 2014.

[26] R. K. Bhaskar, K. K. Deo, U. Neupane et al., "A Case Control Study on Risk Factors Associated with Low Birth Weight Babies in Eastern Nepal," International Journal of Pediatrics, vol. 2015, Article ID 807373, 7 pages, 2015. 
[27] H. Demelash, A. Motbainor, D. Nigatu, K. Gashaw, and A. Melese, "Risk factors for low birth weight in Bale zone hospitals, South-East Ethiopia : a case-control study," BMC Pregnancy and Childbirth, vol. 15, no. 1, article 264, 2015.

[28] T. Gebrehawerya, E. Admasu, and M. Gebremedhin, "Determinants of low birth weight among mothers who gave birth in Debremarkos Referral Hospital, Debremarkos Town, East Gojam, Amhara Region, Ethiopia," Journal of Neonatal and Pediatric Medicine, vol. 4, no. 1, 2018.

[29] H. I. K. Amanuel, T. Kovach, F. Lemma, K. Sethuraman, A. E. Sommerfelt, and T. Teka, "A tool to support nutrition advocacy in Ethiopia: Ethiopia profiles 2012 estimates final report," Federal Democratic Republic of Ethiopia Ministry of Health and USAID, Washington, DC, and Addis Ababa, Ethiopia, 2013.

[30] A. Endalamaw, E. H. Engeda, D. T. Ekubagewargies, G. M. Belay, and M. A. Tefera, "Low birth weight and its associated factors in Ethiopia: a systematic review and meta-analysis," Italian Journal of Pediatrics, vol. 44, no. 1, p. 141, 2018.

[31] FAO, FANTA, Minimum Dietary Diversity for Women: A Guide for Measurement, FAO, Rome, 2016.

[32] M. Gebremedhin, F. Ambaw, E. Admassu, and H. Berhane, "Maternal associated factors of low birth weight: a hospitalbased cross-sectional mixed study in Tigray, Northern Ethiopia," BMC Pregnancy and Childbirth, vol. 15, no. 1, article 222, 2015.

[33] S. Feresu, S. Harlow, and G. Woelk, "Risk factors for low birthweight in Zimbabwean women: a secondary data analysis," PLoS One, vol. 10, no. 6, article e0129705, 2015.

[34] B. Gizaw and S. Gebremedhin, "Factors associated with low birthweight in North Shewa zone, Central Ethiopia: casecontrol study," Italian Journal of Pediatrics, vol. 44, no. 1, article 76, 2018.

[35] H. Mulatu, K. Zepre, M. Betre, and G. Hailemicael, "Magnitude and factors associated with low birth weight among new born in selected public hospitals of Addis Ababa, Ethiopia, 2016," Global Journal of Medical Research, vol. 17, no. 5, 2017.

[36] G. Aea, "Epidemiology of low birth weight in the town of Sidi Bel Abbes (west of Algeria): a case-control study," Nutrition \& Food Sciences, vol. 4, no. 2, 2014.

[37] K. Zenebe, T. Awoke, and N. Birhan, "Low birth weight \& associated factors among newborns in Gondar town, North West Ethiopia: institutional based cross-sectional study," Indo Global Journal of Pharmaceutical Sciences, vol. 4, no. 2, pp. 94802, 2014.

[38] A. Jammeh, J. Sundby, and S. Vangen, "Maternal and obstetric risk factors for low birth weight and preterm birth in rural Gambia: a hospital-based study of 1579 deliveries," Open Journal of Obstetrics and Gynecology, vol. 1, no. 3, pp. 94-103, 2011.

[39] T. Azeze and B. Haji, "Assessment of knowledge gap and constraints affecting consumption of standardized dairy products in Sidama and Gedeo Zone, Southern Ethiopia," Journal of Scientific and Innovative Research, vol. 6, no. 1, 2017.

[40] N. Assefa, Y. Berhane, and A. Worku, "Wealth status, Mid Upper arm circumference (MUAC) and antenatal care (ANC) are determinants for low birth weight in Kersa, Ethiopia," PLoS One, vol. 7, no. 6, article e39957, 2012.

[41] EDHS, "DHS model questionnaires 2017," https://dhsprogram .com/What-We-Do/Survey-Types/DHS-Questionnaires.cfm. 